\title{
Molecular epidemiology of human respiratory syncytial virus in Uruguay: 1985-2001 - A Review
}

\author{
Juan Arbiza ${ }^{+}$, Adriana Delfraro, Sandra Frabasile
}

\author{
Sección Virología, Facultad de Ciencias, Universidad de la República, Iguá 4225, Casilla Postal 11400, Montevideo, Uruguay
}

The variability of the G glycoprotein from human respiratory syncytial viruses (HRSV) (groups A and B) isolated during 17 consecutive epidemics in Montevideo, Uruguay have been analyzed. Several annual epidemics were studied, where strains from groups $A$ and B circulated together throughout the epidemics with predominance of one of them. Usually, group A predominates, but in some epidemics group B is more frequently detected. To analyse the antigenic diversity of the strains, extracts of cells infected with different viruses of group A were tested with a panel of anti-G monoclonal antibodies (MAbs). The genetic variability of both groups was analyzed by sequencing the $C$ terminal third of the $G$ protein gene. The sequences obtained together with previously published sequences were used to perform phylogenetic analyses. The data from Uruguayan isolates, together with those from the rest of the world provide information regarding worldwide strain circulation. Phylogenetic analyses of HRSV from groups A and $B$ show a model of evolution analogous to the one proposed for influenza $B$ viruses providing information that would be beneficial for future immunization programs and to design safe vaccines.

Key words: human respiratory syncytial virus - variability- Uruguay

Human respiratory syncytial virus (HRSV) is a member of the genus Pneumovirus, in the subfamily Paramyxovirinae, family Paramyxoviridae (Van Regenmortel et al. 2000). HRSV is the leading cause of severe infectious diseases of respiratory tract of infants and young children worldwide, yearly producing large epidemics (Collins et al. 2001). Interestingly, HRSV can infect children in the presence of maternal antibody, and the partial protection in a natural infection, allows re-infections throughout life. In temperate climates, HRSV epidemics occur annually in the winter months, whereas in tropical climates, the outbreaks are associated with the rainy season (Cane 2001).

In developed countries, the impact of HRSV has been reported, estimating for example that in the United States, HRSV is responsible for 51,000-82,000 hospitalizations and for 90-700 deaths per year (Anderson et al. 1990, Shay et al. 1999, Leader \& Kohlhase 2003). Although much less is known in developing countries, one third of all deaths in children younger than 5 years of age have been estimated to be caused by acute respiratory infections. Within them, HRSV is responsible for more than a quarter (26$96 \%$ ) of the hospitalized cases of acute respiratory viral infections (reviewed by Weber et al. 1998).

HRSV contains a non-segmented negative sense

Financial support: in part by three consecutive grants from European Union (1991-2001)

${ }^{+}$Corresponding author present address: Laboratório de Vírus Respiratórios, Instituto Oswaldo Cruz-Fiocruz, Av. Brasil 4365, 21045-900, Rio de Janeiro, RJ, Brasil.

E-mail: jarbiza@fcien.edu.uy

Received 17 November 2004

Accepted 17 February 2005 single-stranded RNA that encodes 11 proteins. Two main antigenic groups A and B have been identified by distinct patterns in reactivity with panels of monoclonal antibodies (MAbs) (Anderson et al. 1985, Mufson et al. 1985). These two principal antigenic groups were correlated to genetically distinct viruses (Cristina et al. 1990). Also, extensive antigenic and genetic variation has been described within each main group A and B with panels of monoclonal antibodies, reverse transcription-polymerase chain reaction (RT-PCR) and endonucleases restriction analysis or nucleotide sequencing (García-Barreno et al. 1989, Cane \& Pringle 1992, 1995, García et al. 1994, Melero et al. 1997, Martínez et al. 1999, Sullender 2000).

The attachment $(\mathrm{G})$ glycoprotein is the most variable both between and within the two groups (Johnson et al. 1987). Accumulation of sequence changes at certain positions with time, reflect an evolution mode under selective pressure (Cane \& Pringle 1995, Melero et al. 1997). The variability in the $G$ protein is concentrated in two hypervariable regions in the ectodomain, separated by a conserved 13 amino acids motif (Cane et al. 1991, Sullender et al. 1991).

Studies on molecular epidemiology of HRSV have focused on this protein, showing several evolutionary lineages among isolates of both groups (Cane et al. 1991, Garcia et al. 1994, Peret et al. 1998, Martinez et al. 1999, Venter et al. 2001, Frabasile et al. 2003, Moura et al. 2004). The domain located near the C-terminal region of the $\mathrm{G}$ protein reflects the entire $\mathrm{G}$ gene variability; it has therefore been used in phylogenetic analyses for molecular epidemiology studies (Peret et al. 1998, Martínez et al. 1999).

In Uruguay, a country with a typical temperate climate, HRSV epidemic occurs annually in the late fall, winter and early spring (Hortal et al. 1988). HRSV is responsible for 40 to $60 \%$ of serious lower respiratory tract disease in children less than one year old who require hospitalization in our country (Hortal et al. 1986). Also, in a 
study in order to identify agents associated with acute respiratory tract infections (ARI) in children less than 5 years old, a longitudinal community study was undertaken in Montevideo, Uruguay. During this study, two kinds of child populations were studied: a) children visited at home by pediatricians (group 1), and b) children with an ARI episode who attended an outpatient clinic (group 2). HRSV was the most frequently recovered viral agent detected, accounting for $67.9 \%$ in group 1 and $58.1 \%$ in group 2 (Hortal et al. 1990).

The molecular epidemiology of HRSV in Uruguay has been studied during 17 consecutive years (García et al. 1994, Martínez et al. 1999, Frabasile et al. 2003, Blanc et al. 2004). The data obtained from Uruguayan isolates and those from the rest of the world provide information regarding strain circulation worldwide and offered a model of HRSV evolution analogous to the one described for influenza B virus. The results of the present study would be beneficial to future immunization programs and to design safe vaccines.

\section{Circulation of antigenic groups A and B}

The occurrence of the main antigenic groups A and B in each Uruguayan epidemic period during 1985-2001 (Russi et al. 1989, Arbiza et al. 2003) is represented in Fig. 1. Both groups circulated together in most of the outbreaks, as seen in countries from the Northern (Akerlind \& Norby 1986, Waris 1991) and Southern hemisphere (Salomon et al. 1988, Siqueira et al. 1991, Carballal et al. 2000). A wide predominance of HRSV group A strain circulation was observed during the 17 consecutive periods analyzed, in agreement with most of the previous reports. In some countries where both groups co-circulated, group A was always predominant (Storch \& Park 1987, Morgan et al. 1987, Carballal et al. 2000).

The results of the distribution of HRSV groups showed a pattern of alternating predominance between both groups throughout the period studied. Thus, overall, the pattern of 2 to 4 consecutive years of group A predominance was followed by a single intervening year in which group B strains were dominant. This switch in predominance, where a regular pattern of group prevalence occurs, has been reported previously in very few countries, as in Finland, where a regular change of group prevalence was observed in a two-year cycle (Waris 1991).

This pattern of variable dominance in the occurrence of different HRSV group strains may suggest a possible role of the group-specific immune response in HRSV epidemics.

\section{Genetic analysis of HRSV strains}

Seventy-four strains of HRSV, 37 from group A and 37 from group B isolated during 14 consecutive epidemics (1987-2001) from Mon-tevideo, Uruguay were studied.

In order to detect the genetic variability of the isolates, the 3' terminal third of the G glycoprotein gene was sequenced. Although the entire PCR amplification of the $\mathrm{G}$ gene was carried out, only the $3^{\prime}$ terminal third was sequenced [563-922 nucleotide (nt) to group A and 652922 to group B]. In order to assign genotypes to the Uruguayan isolates and to compare with other strains isolated worldwide, sequences belonging to previously described genotypes from US, United Kingdom, Canada, South Africa, Mozambique, Sweden, Seoul, Mexico, Spain, and Japan were included in the analysis.

Fourteen Uruguayan group B strains isolated in 1991, 1992, 1994, and 1996 were not included in the present analysis, because sequences of terminal $156 \mathrm{nt}$ of the $\mathrm{G}$ gene were not available (reviewed in Martínez et al. 1999).

The phylogenetic relationships between the isolates were analyzed under Maximum Parsimony criterion. Since most of the published sequences comprised the last 270 $\mathrm{nt}$ of the $\mathrm{G}$ protein, the same fragment was taken into account in the phylogenetic analysis.

Phylogenetic analysis of the last 270 nucleotides of the $\mathrm{G}$ gene from 67 distinct group $\mathrm{A}$ isolates revealed two main branches (Fig. 2), one of them with very few strains, while the other has several sub-branches, in agreement with other reports from several countries (García et al. 1994, Peret et al. 1998, Coggins et al. 1998, Cane 2001, Venter et al. 2001, Frabasile et al. 2003, Moura et al. 2004). The branch with very few sub-branches clustered isolates with bootstrap value of $100 \%$ within GA1 genotype. The other principal branch with bootstrap value of $100 \%$ is divided into several sub-branches which grouped distinct genotypes.

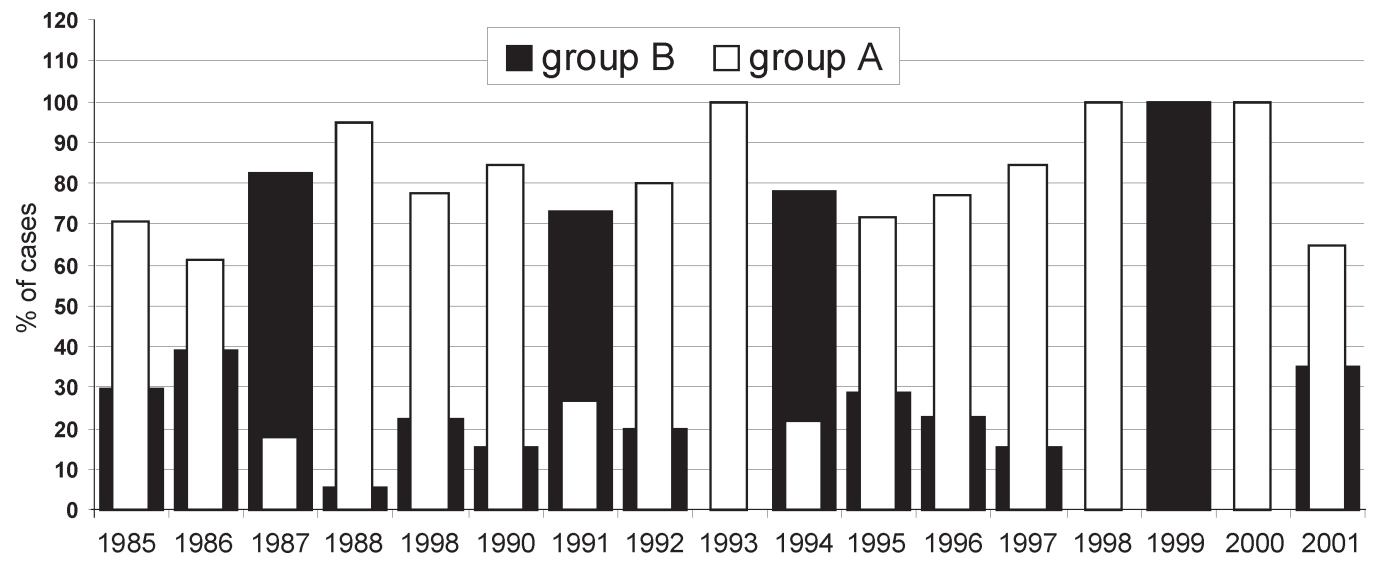

Fig. 1: annual distribution of human respiratory syncytial virus groups A and B during 1985-2001 in Uruguay. 
Sixteen isolates clustered within GA5 genotype with a $98 \%$ bootstrap support, 13 in GA2 with a bootstrap of $69 \%$, four in GA1 with $100 \%$ bootstrap support and three in GA3. No Uruguayan strains clustered in genotypes GA4, GA6, GA7 or SAA1. As seen in previous reports, GA3 genotype has a low statistic support (Cane 2001, Venter et al. 2002, Frabasile et al. 2003). In Peret et al.
(2000), genotype GA3 split into three new genotypes (GA3, GA6, and GA7) when new sequences were added to the analysis. It is thus possible that further addition of new sequences may allow the consolidation of groups with poor support or even the generation of new ones. Thus, an Uruguayan strain not assigned in previous studies (Sullender 2000), Mon/4/90, now clusters in GA3 geno-

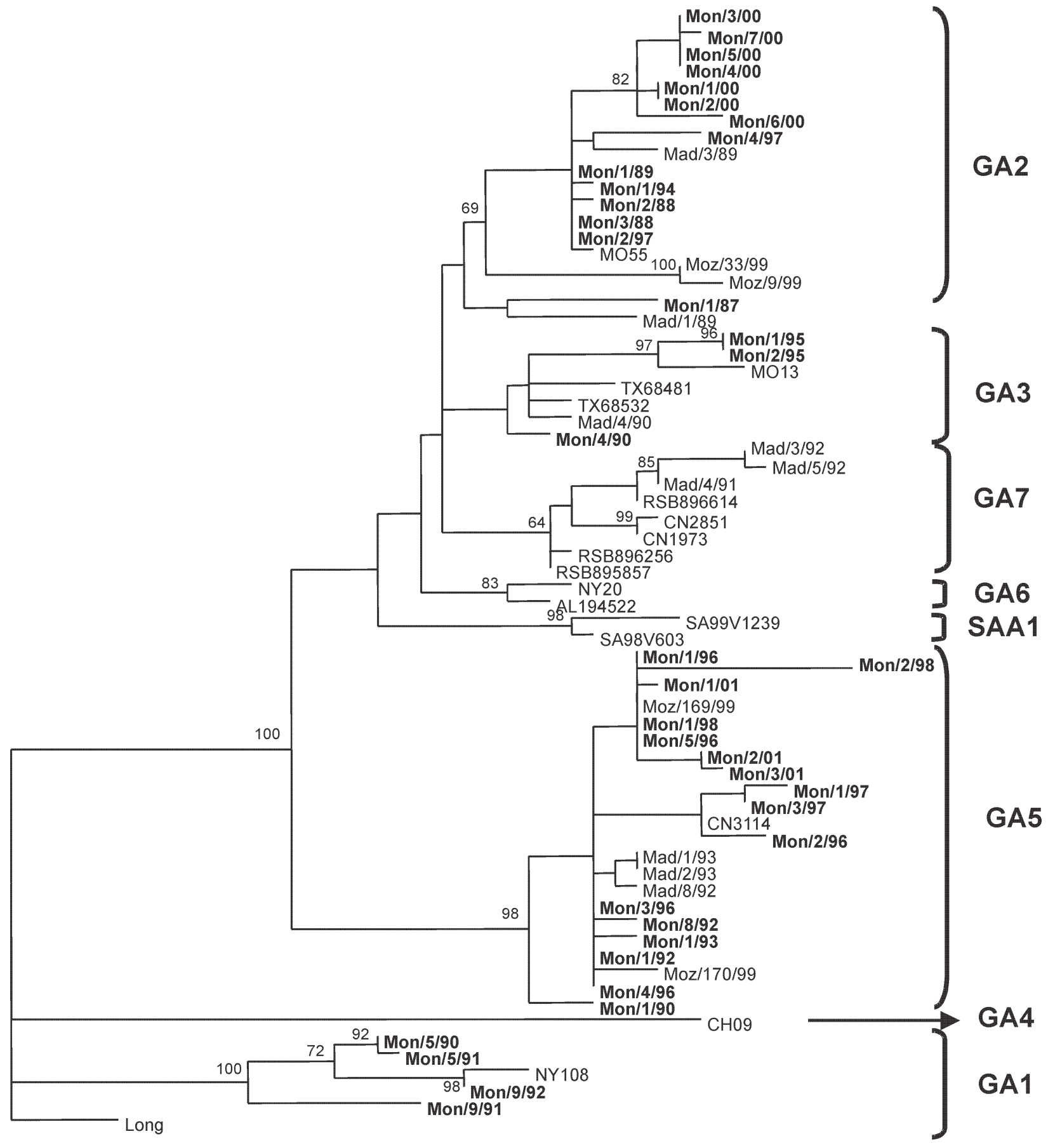

1

Fig. 2: phylogenetic analysis of the $G$ gene of group A human respiratory syncytial virus. The $C$ terminal third of the $G$ gene from 37 Uruguayan strains and 30 sequences downloaded from GenBank belonging to previously described genotypes were analyzed under Maximum Parsimony criterion. Supports of the nodes were obtained through 1000 bootstrap pseudo-replicates. Genotypes are indicated in brackets. 
type, while the strain Mon/1/87 still remains unclassified.

Phylogenetic analysis of the last 270 nucleotides of the $\mathrm{G}$ gene from 76 distinct group $\mathrm{B}$ isolates did not reveal the pattern displayed for group A strains (Fig. 3). Uruguayan viruses clustered into several genotypes: SAB3, SAB2, GB3, GB4, and GB1. Except for GB3, which does not show a significant bootstrap support, these groups display bootstrap values ranging 76-100\%. Two strains (Mon/10/94 and Mon/7/89) remained unclassified, although related to the only strain belonging to GB2 genotype (CH93-9B) according to Venter et al. (2001).

Moreover, some Uruguayan strains grouped into two new clades with bootstrap supports of 80 and $87 \%$. These clades were named URU1 and URU2. URU1 contains isolates from 1999 and 2001 and a strain from Japan (SO2-19). URU2 contains only Uruguayan strains from outbreaks 1990, 1991, and 2001 (Fig. 3). Interestingly, two isolates from the year 2001 (Mon/7/01 and Mon/8/01) have a sixnucleotide insertion after nucleotide 694 , which is translated into a two amino acid duplication (KE, residues 225 and 226) (Fig. 6).

In some outbreaks both for antigenic groups A and B, viruses isolated in the same year grouped together in the same clade (e.g. group A viruses isolated in 2000 clustered in GA2 and group B viruses isolated in 1999 clustered in $\mathrm{SAB} 3$ ). On the other hand, viruses from group $\mathrm{A}$ isolated in 1997 and from group B isolated in 2001 were grouped in different branches.

Phylogenetic analyses including sequences from Uruguay and worldwide isolates from both groups (Figs 2, 3) show that viruses isolated in the same place during the same epidemic (e.g., Mon/2/97 and Mon/1/97 for group A) may be more distantly related than viruses isolated in two distinct places and also in different epidemic periods (e.g., Mon/3/94 and SA99V439 for group B).

Phylogenetic trees of both groups reveal a model of HRSV evolution similar to that of influenza $B$ virus, where several cocirculating lineages coexist during the same epidemic. Thus, these viruses show a rapid spread and a temporal rather than geographical variation. Moreover, HRSV shows an accumulation of mutations over time that results in amino acid substitutions, mainly in the two hypervariable regions of the G glycoprotein, revealing the positive selection of variants by the immune pressure of the human population (Cane \& Pringle 1995, Melero et al. 1997).

\section{Genetic-antigenic pattern correlation}

To correlate the genetic variability of the $G$ protein from the Uruguayan isolates with antigenic changes, extracts of infected cells with viruses only from group A were tested by ELISA with a panel of four MAbs directed against the $\mathrm{G}$ protein, kindly provided by Dr JA Melero from Instituto de Salud Carlos III, Madrid, Spain. Unfortunately there was not a panel of MAbs available to perform an assay against HRSV group B strains. The four MAbs used in this analysis were directed against Mon/3/ 88 strain (prefix 021), this strain was included as reference also in phylogenetic analysis. One of them recognizes conserved epitopes $(021 / 1 \mathrm{G})$, another recognizes group A specific epitopes $(021 / 2 \mathrm{G})$ and the other two identify variable epitopes $(021 / 8 \mathrm{G}$ and $0 / 21 / 9 \mathrm{G})$ (Martinez et al. 1997).

The antigenic patterns obtained by ELISA analysis were compared with the genetic variability found in each isolate. Fig. 4 shows a tree including only the Uruguayan sequences, Long and Mon/3/88 reference strains, and the reactivity of each isolate with the MAbs assayed. All the strains reacted with MAbs that identify conserved epitopes or group A specific epitopes $(021 / 1 \mathrm{G}$ and $021 / 2 \mathrm{G}$ respectively). A great variability of reactivity is observed with strain specific MAbs (021/8G and 021/9G).

The two main branches of the phylogenetic tree correlate with two principal antigenic categories; in addition, other minor antigenic changes could be related to particular lineages. Thus, GA1 genotype showed a loss of reactivity with the strain specific MAbs. All the isolates grouped in the GA5 genotype present a greater variability in reactivity with the strain specific MAbs in comparison with the one observed for the isolates belonging to GA2 and GA3 genotypes.

These observations denote a clear correlation between genetic and antigenic relatedness in the $\mathrm{G}$ protein of HRSV group A.

\section{Amino acid analysis}

The deduced amino acid sequences of the region examined (amino acid 213 to end for group A and 211 to end for group B) from Uruguayan strains and those of Long and $\mathrm{CH} 18537$ as standards are shown in Figs 5 and 6. The sequence changes found between the isolates were: i) amino acid replacements, ii) changes in the stop codon positions, and iii) insertion of amino acids by duplication of sequences (only for group B strains).

Differences in the length of the $G$ protein from strains of both groups were observed (Figs 5, 6). For group A strains the deduced sequence would encode proteins of 297 or 298 amino acids. Those with 297 amino acids have two consecutive stop codons after nucleotide 906 of the $\mathrm{G}$ protein gene, and those with 298 amino acids mutated the first stop codon to a coding triplet. In HRSV group B isolates, more variability is seen, so the deduced length of the protein would be: 292, 295, 297 or 299.

A limited variation in protein length has been observed among the $\mathrm{G}$ protein of group A viruses in comparison with group B strains. The changes in protein length correlated with the position of viruses in the phylogenetic tree. For instance, most viruses of group A grouped into GA1 and GA2 genotypes had a deduced G protein length of 297 amino acids, and viruses grouped in GA3 and GA5 genotypes had a deduced $\mathrm{G}$ protein length of 298 amino acids.

Any of the Uruguayan group B strains resemble the reference strain $\mathrm{CH} 18537$, which has a 292 amino acids length. As was noted in previous studies (Martínez et al. 1997), most of the strains isolated in the eighties (1989), grouped together in GB1 and have a deduced length of 299 amino acids. As an exception, Mon/7/89 strain presented a deduced length of 295 amino acids, but remained unclassified according to the actual genotypes. Furthermore, most of the recent isolates (1991 to 2001) show a deduced length of 295 amino acids and cluster in several 


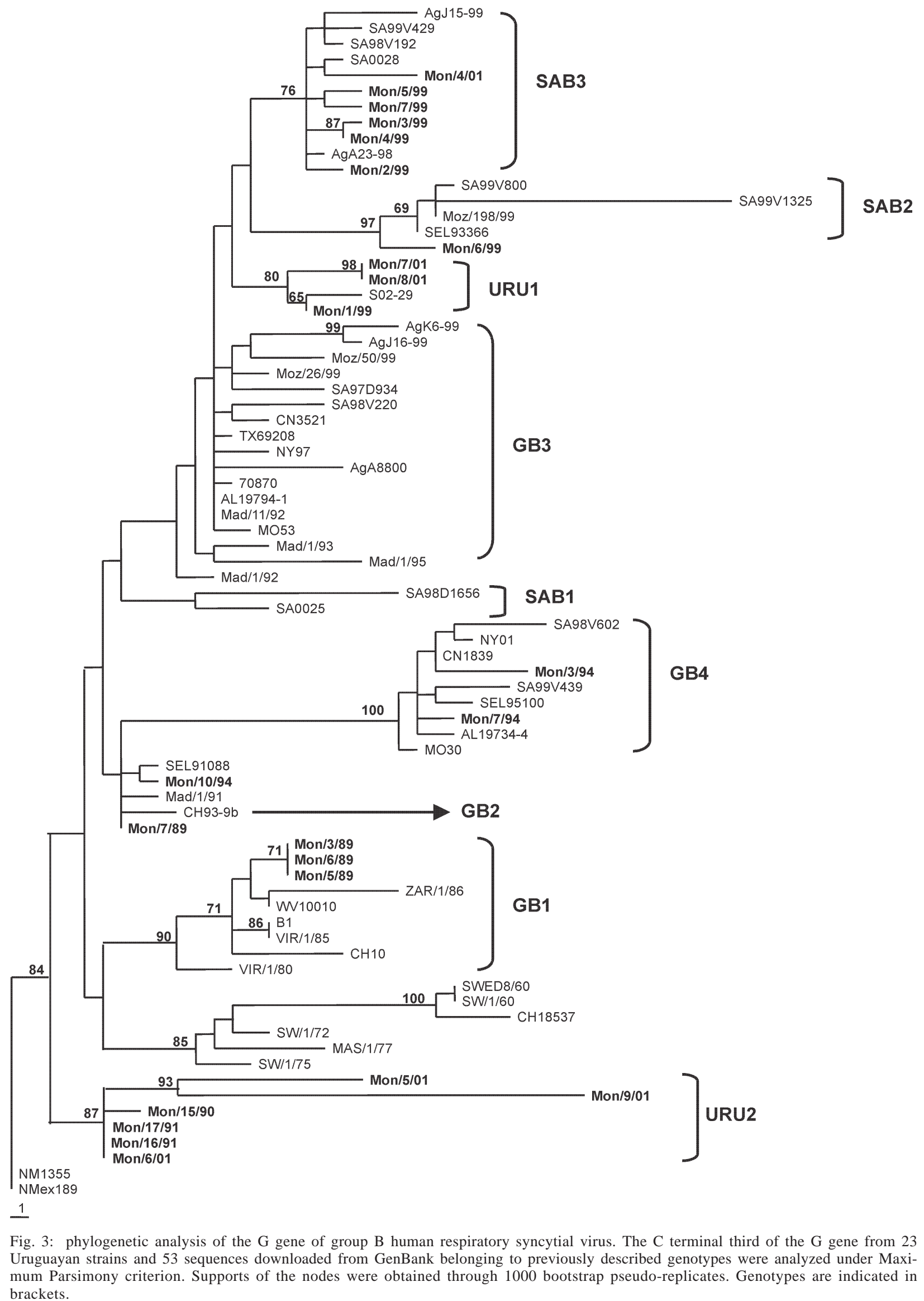


genotypes (SAB3, SAB2, GB4, Uru2, unclassified strains). In addition, two of the three strains clustered in URU1 have an amino acid duplication, which would give rise to a protein of 297 amino acids. The variability in stop codon usage for group B strains highlights the relevance of this mechanism in the generation of HRSV diversity.

Several of the amino acid substitutions observed in the strains could be genotype-specific associated as was previously described (Peret et al. 1998, Venter et al. 2001). In Table I are summarized some of these substitutions in the genotypes of group A. Also, genotype-specific amino acid substitutions were observed among group B strains. For example, in GB4 genotype: Pro-217-Ser, Pro-220-Ser, Met-223-Ser, Lys-225-Arg, Asn-231-Asp, Lys-235-Glu, Gln249-ArgR, Lys-259-Asp, and Glu-242-Gly for the genotype URU1, and Lys-259-Gly for genotype SAB3 (Fig. 6).

\section{Correlation between reactivity with MAbs and amino acids substitutions}

Escape mutants selected with the MAbs used in this study identified residues within the C-terminal third of the $\mathrm{G}$ protein essential for the integrity of some epitopes (Martinez et al. 1997). The comparison of the amino acid changes selected in the escape mutants with the G pro- tein sequences reported from the Uruguayan strains could tentatively associate certain amino acid changes of natural isolates with the loss of epitopes recognized by strain specific MAbs (Table II).

Two amino acids (20 and 244) in the $\mathrm{G}$ protein have been associated in the mapping of the MAb 021/9G (Martinez et al. 1997). All the isolates grouped into the GA1 genotype did not react at all with 021/9G MAb, whereas the other strains grouped into the GA2, GA3, and GA5 genotypes with the sole exception of the Mon/ $4 / 90$ and Mon/2/98 strains react with this MAb. As is represented in Table II, and shown in Fig. 3, the isolates that did not react with this Mab, changed the amino acid Arg-244-to-Thr, Ile or Ser. Thus the same amino acid Arg244 was changed into the isolates analyzed and in the escape mutant resistant to 021/9G MAb, even in one of them the same change Arg-244-to-Ser was identified (Martínez et al. 1997).

The amino acids 237 and 239 of the G protein have been associated to the integrity of the epitope recognized by the MAb 021/8G. Most of the isolates from GA5 genotype and all of the strains grouped in GA1 genotype did not react with 021/8G MAb. No changes in natural isolates that coincide with the change selected in escape

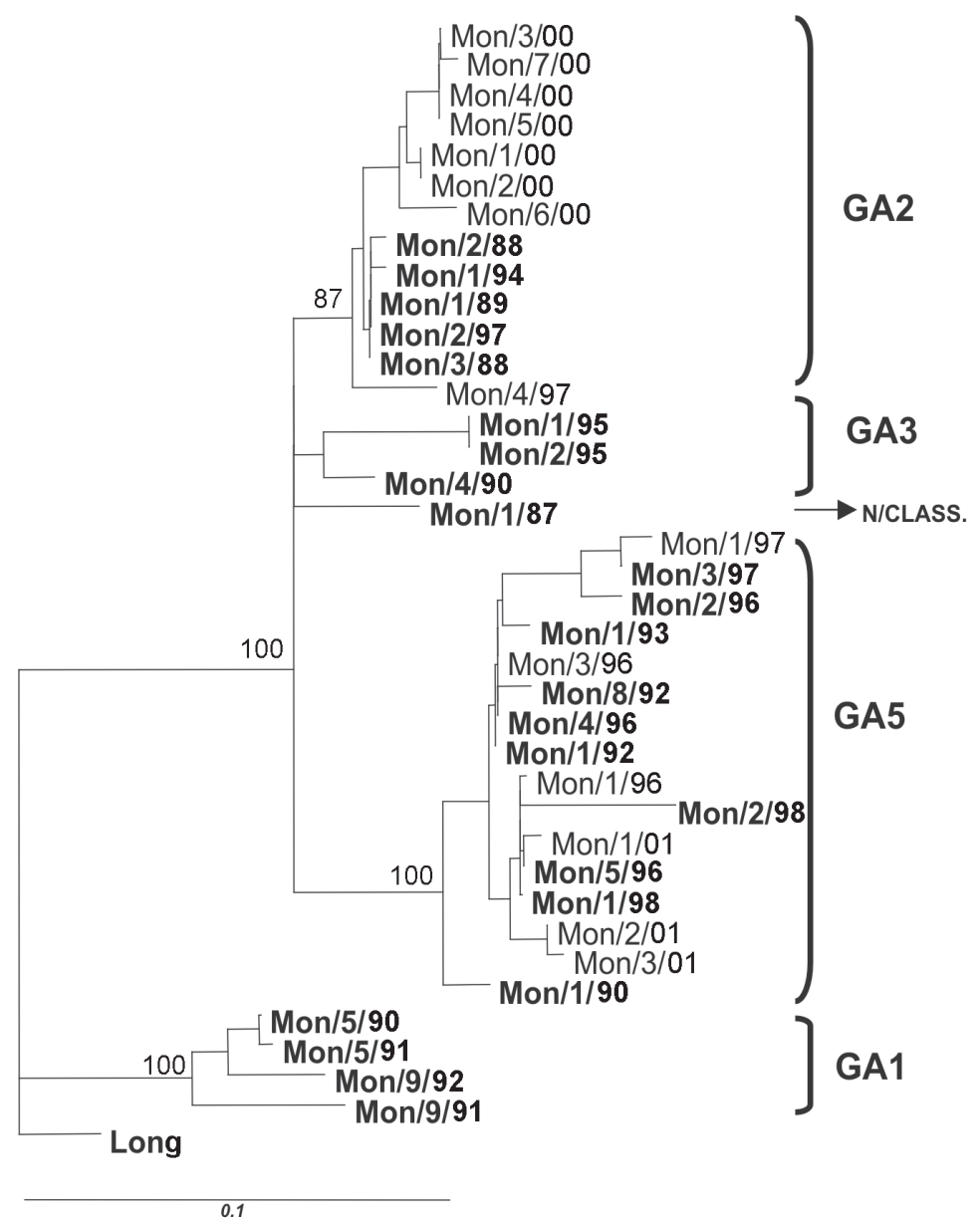

\begin{tabular}{|c|c|c|c|c|c|}
\hline Strains & $\frac{0}{\stackrel{N}{N}}$ & 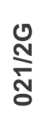 & 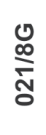 & 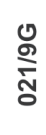 & $\sum_{\substack{0 \\
0}}^{\stackrel{0}{0}}$ \\
\hline Mon/2/88 & 96 & 96 & & & GA2 \\
\hline Mon/1/94 & & & & & GA2 \\
\hline Mon/1/89 & & & & & GA2 \\
\hline Mon/2/97 & & & & & GA2 \\
\hline Mon/3/88 & & & & & ref. \\
\hline Mon/1/95 & & & & & GA3 \\
\hline Mon/2/95 & & & & & GA3 \\
\hline Mon/4/90 & & & & & GA3 \\
\hline Mon/1/87 & & & & & n/class \\
\hline Mon/3/97 & & & & & GA5 \\
\hline Mon/2/96 & & & & & GA5 \\
\hline Mon/4/96 & & & & & GA5 \\
\hline Mon/1/93 & & & & & GA5 \\
\hline Mon/8/92 & & & & & GA5 \\
\hline Mon/1/92 & & & & & GA5 \\
\hline Mon/2/98 & & & & & GA5 \\
\hline Mon/5/96 & & & & & GA5 \\
\hline Mon/1/98 & & & & & GA5 \\
\hline Mon/1/90 & & & & & GA5 \\
\hline Mon/5/90 & & & & & GA1 \\
\hline Mon/5/91 & & & & & GA1 \\
\hline Mon/9/92 & 863 & 96 & & & GA1 \\
\hline Mon/9/91 & & & & & GA1 \\
\hline Long & & & & & ref. \\
\hline Epitope category & C & GS & SS & SS & \\
\hline
\end{tabular}

Fig. 4: phylogenetic and antigenic analysis of group A human respiratory syncytial virus. The reactivities of viruses in ELISA with the monoclonal antibodies indicated at the top, relative to reactivities of the Mon/3/88 strain against the monoclonal antibodies were directed, are shown at the right (positive $\boldsymbol{\square}$, intermediate $\square$ or negative $\square$ ). 


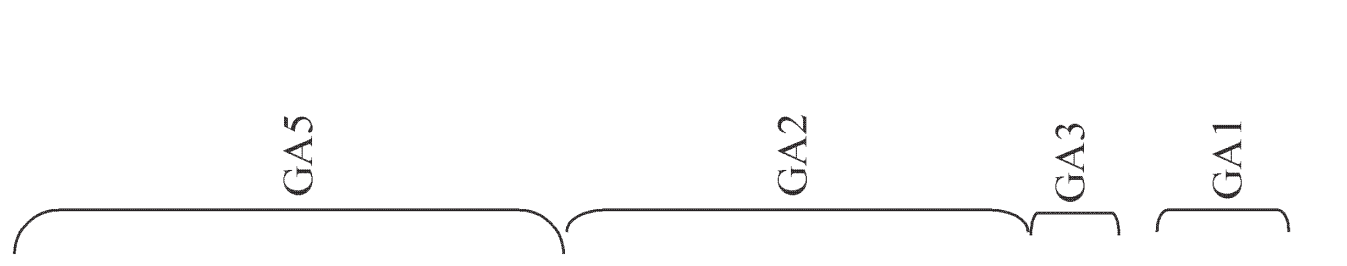

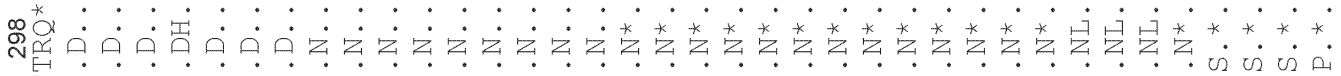

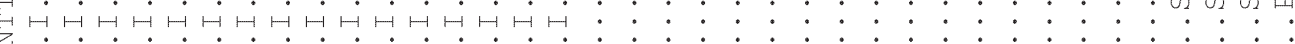

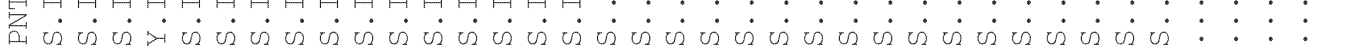

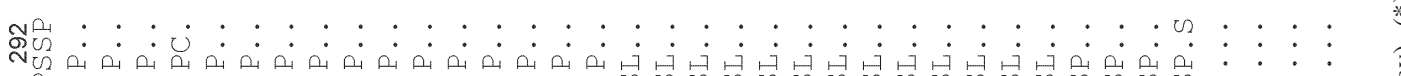

o : : : : : : : : : : : : : : : : : : : : : : : : : : :

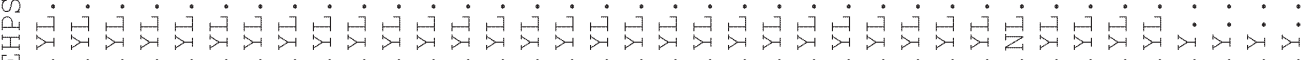

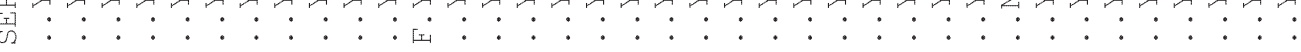

هึ

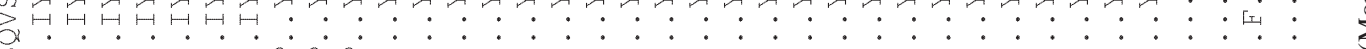

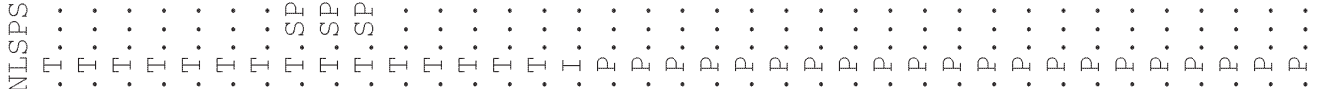

: : : : : : : : : : : : : : : : : : : :

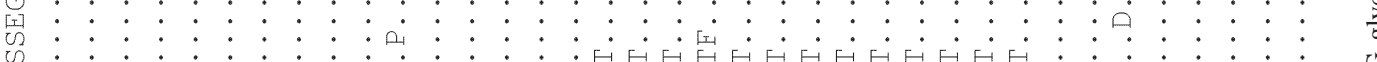

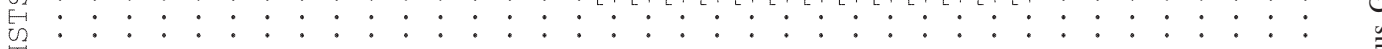

覀

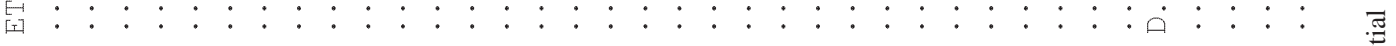

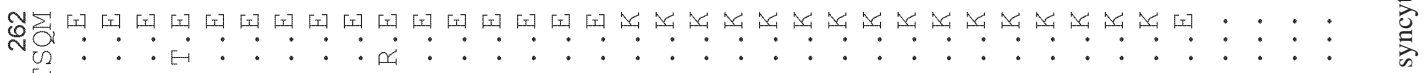

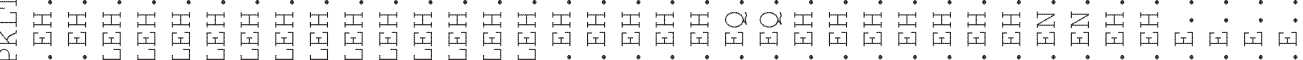

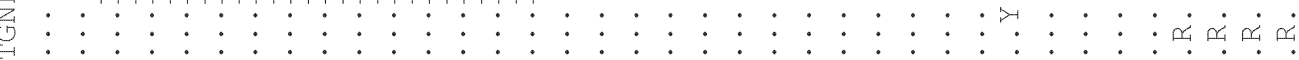

लै⿴囗大

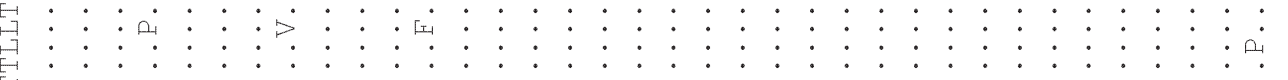

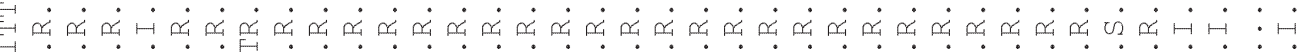

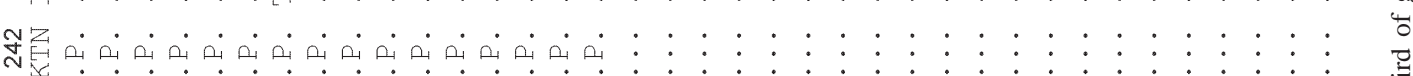

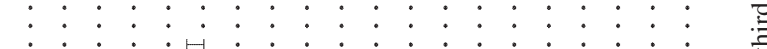

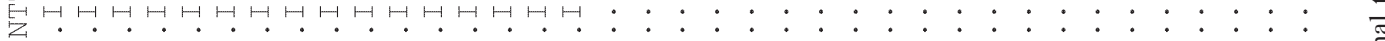

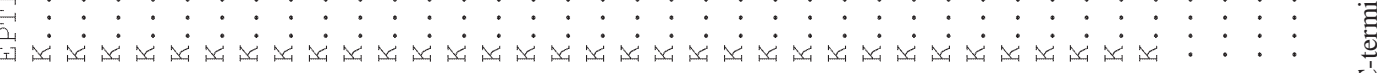

쓰ำด: : : : : : : : : : : : : : : : : : : : : : : : : : : :

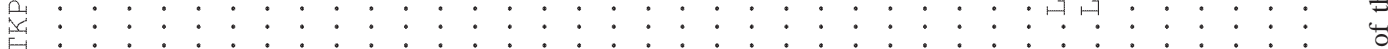

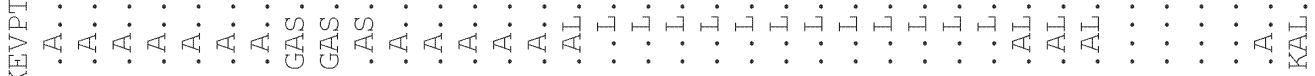

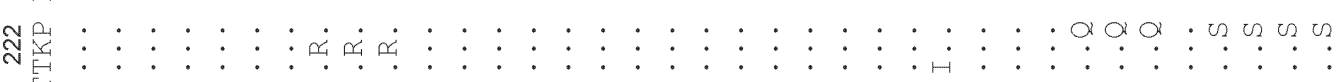

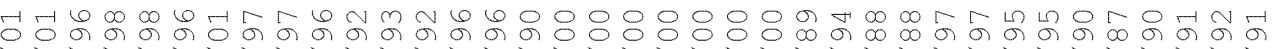

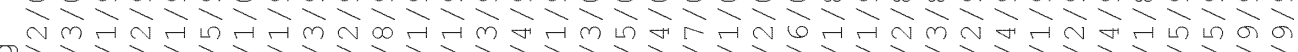
G) 


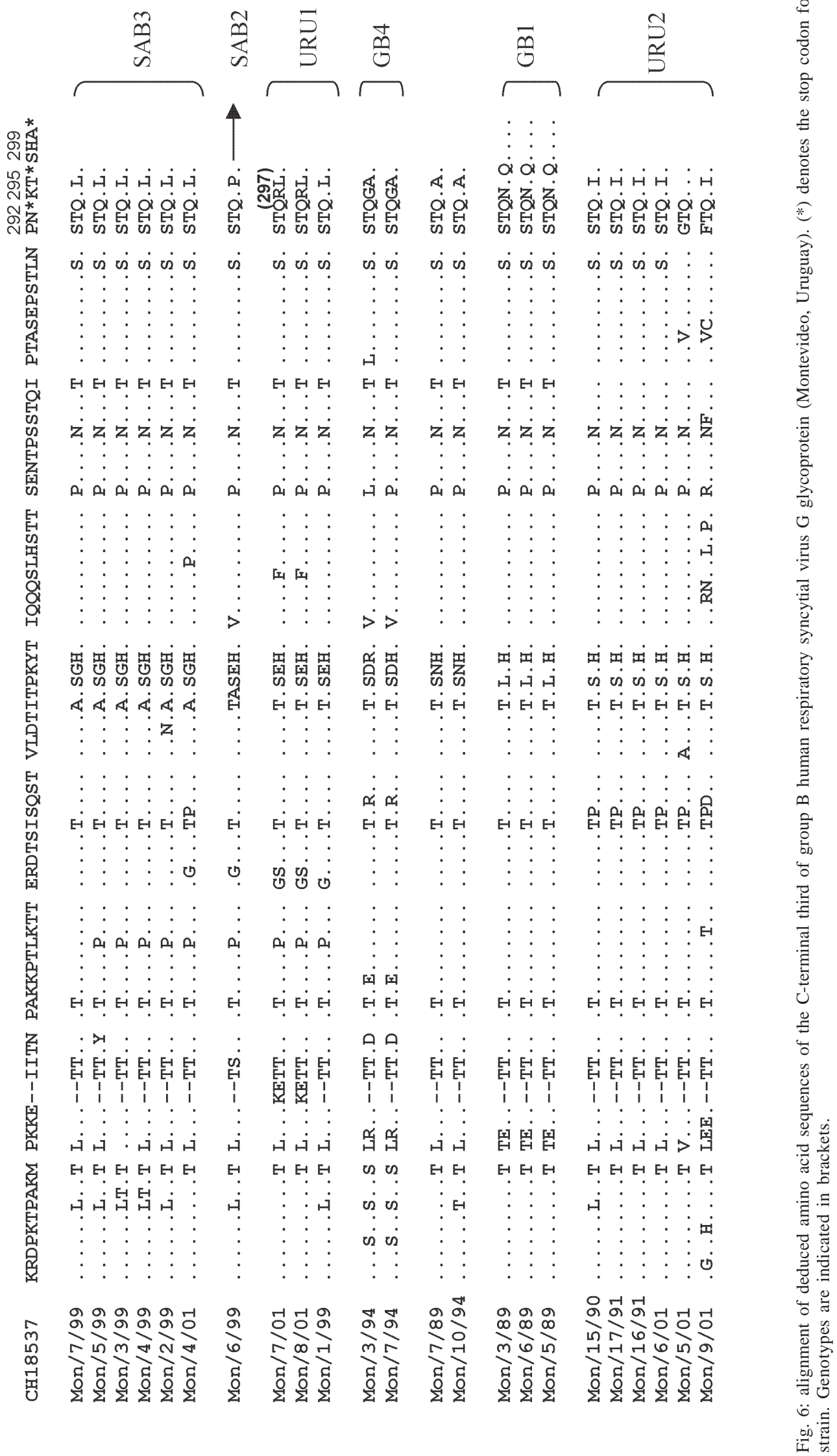


TABLE I

Amino acid substitutions genotype specific observed among the human respiratory syncytial virus group A strains

\begin{tabular}{lllll}
\hline Genotypes & \multicolumn{1}{c}{ GA1 } & GA5 & GA2 & GA3 \\
\hline & Lys-222-Ser & Thr-238-Ile & Ser-269-Thr & Gln-298-Leu \\
Lys-233-Glu & Thr-241-Pro & Ser-290-Leu & \\
Gly-254-Arg & Thr-295-Ile & \\
Aminoacid & His-258-Leu & & \\
Gubstitutions & Glu or Lys-262-Met & & \\
& Leu-256-Phe & & \\
& Tyr-289-Ser & & \\
& Tyr-281-Ile & & \\
& Leu-286-Pro & & \\
& Ser-293-Pro & & \\
\hline
\end{tabular}

TABLE II

Amino acid (Aa) changes relatedness with the reactivity of monoclonal antibodies

\begin{tabular}{lll}
\hline MAbs & $\begin{array}{c}\text { Aa changes in } \\
\text { escape mutants }\end{array}$ & $\begin{array}{l}\text { Aa changes } \\
\text { in isolates }\end{array}$ \\
\hline 021/8G & Asn-237-Tyr & $\begin{array}{l}\text { Lys-233-Glu } \\
\text { Thr-238-Ile } \\
\text { Thr-239-Ile } \\
\text { Thr-244-Arg/Ile/Ser }\end{array}$ \\
021/9G & Thr-239-Ala & Asn-21-Thr \\
Arg-244-Ser & Thr-244-Arg/Ile/Ser \\
\hline
\end{tabular}

mutants or nearby changes associated with the loss of epitope $021 / 8 \mathrm{G}$ were found. Interestingly, the isolate Mon/ 4/90, which has changed the same amino acids Thr-239 identified in the escape mutant reacts with the MAb, suggesting that certain changes in natural isolates at the amino acid 239 do not affect the reactivity of the strain with the MAb 021/8G (Figs 3, 6).

The present study is the result of a continuous effort through 17 years in order to analyze the molecular epidemiology of HRSV in Uruguay, and constitutes a contribution to the understanding of the worldwide epidemiology of this relevant infectious agent.

\section{ACKNOWLEDGEMENTS}

To Dr Hermann G Schatzmayr for encouragement to write this review.

\section{REFERENCES}

Akerlind B, Norrby E 1986. Occurrence of respiratory syncytial virus subtypes A and B strains in Sweden. J Med Virol 19: 241-247.

Anderson LJ, Hierholzer JC, Tsou C, Hendry RM, Fernie BN, Stone Y, McIntosh K 1985. Antigenic characterisation of respiratory syncytial virus strains with monoclonal antibodies. J Infect Dis 151: 626-633.

Anderson LJ, Parker RA, Strikas RL 1990. Association between respiratory syncytial virus outbreaks and lower respiratory tract deaths of infants and young children. J Infect Dis 161: 640-646.

Arbiza J, Delfraro A, Frabasile S, Ruchansky D, Vitureira N, de Sierra MJ, Berois M, Blanc A, Facal L, Negro C, Colina R,
Hortal M, Russi JC 2003. Variable dominance of respiratory syncytial virus groups A and B in Uruguay during fourteen consecutive years (1988-2001). Virus Rev \& Res 8: $35-41$.

Blanc A, Delfraro A, Frabasile S, Arbiza J 2004 Genotypes of respiratory syncytial virus group B identified in Uruguay. Arch Virol Oct 11 (Epub ahead of print).

Cane PA 2001. Molecular epidemiology of respiratory syncytial virus. Rev Med Virol 11: 103-116.

Cane PA, Pringle CR 1992. Molecular epidemiology of respiratory syncytial virus: rapid identification of subgroup A lineages. J Virol Methods 40: 297-306.

Cane PA, Pringle CR 1995. Evolution of subgroup A respiratory syncytial virus: evidence for progressive accumulation of amino acid changes in the attachment protein. $J$ Virol 69: 2918-2925.

Cane PA, Matthews DA, Pringle CR 1991. Identification of variable domains of the attachment $(\mathrm{G})$ protein of subgroup A respiratory syncytial viruses. J Gen Virol 72: 2091-2096.

Carballal G, Videla C, Sequeira M Mistchenko A, Requeijo P, Arbiza J 2000. Respiratory syncytial virus: changes in prevalence of subgroups A and B among Argentinean children, 1990-1996. J Med Virol 61: 275-279.

Coggins WB, Lefkowitz EJ, Sullender WM 1998. Genetic variability among group A and group B respiratory syncytial virus in a children's hospital. J Clin Microbiol 36: 35523557.

Collins PL, Chanock RM, Murphy BR 2001. Respiratory syncytial virus. In DM Knipe PM Howley (eds), Fields Virology, 4th ed., Lippincott-Williams and Wilkins, Philadelphia, p. 1443-1486.

Cristina J, López JA, Albo C, García-Barreno B, García J, Melero JA, Portela A 1990 . Analysis of genetic variability in human respiratory syncytial virus by the RNase A mismatch cleavage method: subtype divergence and heterogeneity. Virology 174: 126-134.

Frabasile S, Delfraro A, Facal L, Videla C, Galiano M, de Sierra MJ, Ruchansky D, Vitureira N, Berois M, Carballal G, Russi JC, Arbiza J 2003 Antigenic and genetic variability of human respiratory syncytial viruses (group A) isolated in Uruguay and Argentina:1993-2001. J Med Virol 71: 305312 .

García O, Martín M, Dopazo J, Arbiza J, Frabasile S, Russi JC, 
Hortal M, Pérez Breña P, Martínez I, García-Barreno B, Melero JA 1994. Evolutionary pattern of human Respiratory Syncytial Virus (subgroup A): cocirculating lineages and correlation of genetic and antigenic changes in the $\mathrm{G}$ glycoprotein. J Virol 68: 5548-5559.

García-Barreno B, Palomo C, Penas C, Delgado T, Perez-Breña P, Melero JA 1989. Marked differences in the antigenic structure of human respiratory syncytial virus $F$ and $G$ glycoproteins. J Virol 63(2): 925-932.

Hortal M, Russi J, Arbiza J, Martorell A 1986. Infecciones respiratorias agudas en ninos menores de cinco años hospitalizados. estudio etiologico prospectivo. Rev Med del Uruguay 3: 213-226.

Hortal M, Russi J, Arbiza J, Canepa E, Chiparelli H, Illaramendi A 1988. ARI: community-based study in children from Uruguay. II. Patterns of virus recovery. BOSTID, Washington, D.C.

Hortal M, Benitez A, Contera M, Etorena P, Montano A, Meny M 1990. A community-based study of acute respiratory tract infections in children in Uruguay. Rev Infect Dis 12 (Suppl. 8): S966-973.

Johnson PR, Spriggs MK, Olmsted RA, Collins PL 1987. The $\mathrm{G}$ glycoprotein of human respiratory syncytial viruses of subgroups A and B: extensive sequence divergence between antigenically related proteins. Proc Natl Acad Sci NY 84: 5625-5629.

Leader S, Kohlhase K 2003. Recent trends in severe respiratory syncytial virus (RSV) among US infants, 1997 to 2000. $J$ Pediatr 143: S127-32.

Martínez I, Dopazo J, Melero JA 1997. Antigenic structure of the human respiratory syncytial virus $\mathrm{G}$ glycoprotein and relevance of hypermutation events for the generation of antigenic variants. J Gen Virol 78: 2419-2429.

Martínez I, Valdés O, Delfraro A, Arbiza J, Russi J, Melero JA 1999. Evolutionary pattern of the G glycoprotein of human respiratory syncytial virus from antigenic group B: the use of alternative termination codons and lineage diversification. J Gen Virol 80: 125-130.

Melero JA, García-Barreno B, Martínez I, Pringle CR, Cane PA 1997. Antigenic structure, evolution and immunobiology of human respiratory syncytial virus attachment (G) protein. J Gen Virol 78: 2411-2418.

Moura FE, Blanc A, Frabasile S, Delfraro A, de Sierra MJ, Tome L, Ramos EA, Siqueira MM, Arbiza J 2004. Genetic diversity of respiratory syncytial virus isolated during an epidemic period from children of northeastern Brazil. J Med Virol 74: 156-60.

Morgan LA, Routledge EG, Willcocks MM, Samson AC, Scott R, Toms GL 1987. Strain variation of respiratory syncytial virus. J Gen Virol 68: 2781-2788.

Mufson MA, Orvell C, Rafnar B, Norrby E 1985 Two distinct subtypes of human respiratory syncytial virus. J Gen Virol 66: 2111-2124.

Peret TC, Hall CB, Schnabel KC, Golub JA, Anderson LJ 1998. Circulation patterns of genetically distinct group A and B strains of human respiratory syncytial virus in community. J Gen Virol 79: 2221-2229.

Peret TC, Hall CB, Hammond GW, Piedra PA, Storch GA, Sullender WM, Tsou C, Anderson LJ 2000. Circulation patterns of group A and B human respiratory syncytial virus genotypes in 5 communities in North America. J Infect Dis 181: 1891-1896.

Russi JC, Delfraro A, Arbiza JR, Chiparelli H, Orvell C, Grandien M, Hortal M 1989. Antigenic characterization of respiratory syncytial virus associated with acute respiratory infections in Uruguayan children from 1985 to 1987. J Clin Microbiol 27: 1464-1466.

Salomon HE, Russi JC, Grandien M, Orvell C, Avila MM, Hortal M, Weissenbacher M 1988. Antigenic variants of the respiratory syncytial virus in Argentina and Uruguay. Rev Argent Microbiol 20: 147-150.

Shay DK, Holman RC, Newman RD, Liu LL, Stout JW, Anderson LJ 1999. Bronchiolitis-associated hospitalizations among US children, 1980-1996. JAMA 282: 1440-1446.

Siqueira MM, Nascimento JP, Anderson LJ 1991. Antigenic characterization of respiratory syncytial virus group A and B isolates in Rio de Janeiro, Brazil. J Clin Microbiol 29: 557-559.

Storch GA, Park CS 1987. Monoclonal antibodies demonstrate heterogeneity in the $\mathrm{G}$ glycoprotein of prototype strains and clinical isolates of respiratory syncytial virus. $\mathrm{J} \mathrm{Med}$ Virol 22: 345-356.

Sullender WM 2000. Respiratory syncytial virus genetic and antigenic diversity. Clin Microbiol Rev 13: 1-15.

Sullender WM, Mufson MA, Anderson LJ, Wertz GW 1991. Genetic diversity of the attachment protein of subgroup B respiratory syncytial viruses. J Virol 65: 5425-5434.

Van Regenmortel MHV, Fauquet CM, Bishop DHL, Carstens EB, Estes MK, Lemon SM, Maniloff J, Mayo MA, McGeoch DJ, Pringle CR, Wickner RB 2000. Virus Taxonomy: the Classification and Nomenclature of Viruses, The 7th Report of the International Committee on Taxonomy of Viruses, Academic Press, San Diego, 1167pp.

Venter M, Collinson M, Schoub BD 2002. Molecular epidemiological analysis of community circulating Respiratory Syncytial Virus in rural South Africa: Comparison of virus and genotypes responsible for different diseases manifestations. J Med Virol 68: 452-461.

Venter M, Madhi SA, Tiemessen CT, Schoub BD 2001. Genetic diversity and molecular epidemiology of respiratory syncytial virus over four consecutive seasons in South Africa: identification of new subgroup A and B genotypes. J Gen Virol 82: 2117-2124.

Waris M 1991. Pattern of respiratory syncytial virus epidemics in Finland: two-year cycles with alternating prevalence of groups A and B. J Infect Dis 163: 464-469

Weber MW, Dackour R, Usen S, Schneider G, Adegbola RA, Cane P, Jaffar S, Milligan P, Greenwood BM, Whittle H, Mulholland EK 1998. The clinical spectrum of respiratory syncytial virus disease in The Gambia. Pediatr Infect Dis $J$ 17: 224-230. 